\title{
An In Vitro Study to Investigate the Effect of Various Surface Treatments on the Core-Veneer Shear Bond Strength of Zirconia Restorations: A Scanning Electron Microscope Study
}

\author{
Sumit Katoch ${ }^{1}$ Manjit Kumar ${ }^{1}$ Amrit Khosla ${ }^{1}$ Ritu Batra ${ }^{1}$ Navjot Kaur ${ }^{1}$ \\ ${ }^{1}$ Department of Prosthodontics, Bhojia Dental College and Hospital, \\ Address for correspondence Sumit Katoch, MDS, Department of \\ Prosthodontics, Bhojia Dental College and Hospital, Chandigarh- \\ Nalagarh Road, Budh (Baddi), Solan 173205, Himachal Pradesh, \\ India (e-mail: katoch8889@gmail.com).
}

Dent J Adv Stud 2018;6:14-19

\begin{abstract}
Veneering ceramic to the core is considered to be the weakest part of all-ceramic restorations. Zirconium dioxide, owing to its favorable properties such as high strength, chemical stability, and superior aesthetics, is the material of choice for fabrication of a core. The adhesion between the core and veneering porcelain is based on the same manner in which the connection occurs in metal-ceramic structures. However, the standard procedures for connecting zirconia to hard dental tissues and veneering materials do not achieve the required strength of bonding.

The aim of this study was to investigate different surface treatments of the zirconium dioxide ceramic core for achieving highest adhesive bonding values to veneering

Keywords

- shear bond strength

- zirconium dioxide

- CAD/CAM

- SEM porcelain. The study was primarily designed to investigate the bonding strength of the veneering porcelain to zirconia with in vitro macro shear bond strength test. The samples of zirconia were divided into four groups of 10 specimens, each according to the treatment of zirconium surface, and the results showed the highest bonding values for samples that were treated with the sandblasted group.
\end{abstract}

\section{Introduction}

The advent of all-ceramic systems and their successful use can be credited to their aesthetic properties, biocompatibility, and color stability. However, these materials exhibited a disadvantage of being brittle, and this led to the increasing use of zirconia-based ceramics in recent years. ${ }^{1}$

Zirconia-based ceramics exhibit high mechanical performance, durability, and resistance, increasing the utility of all-ceramic restorations. ${ }^{2}$ The most frequent type of dental zirconium oxide $\left(\mathrm{ZrO}_{2}\right)$ used is yttria-tetragonal zirconia polycrystal (Y-TZP), which provides durability due to the excellent proportionality of transformation from the tetragonal to the monoclinic phase. Y-TZP is a fully tetragonal, finegrained $\mathrm{ZrO}_{2}$ ceramic composed entirely of small metastable tetragonal grains after the addition of $3 \mathrm{~mol} \%$ yttrium oxide $\left(\mathrm{Y}_{2} \mathrm{O}_{3}\right)$ as a stabilizer. ${ }^{3}$
Nowadays, zirconia technology has fallen into step with computer-aided design/computer -aided manufacturing (CAD/CAM) systems that promise to transform everyday dentistry. The majority of CAD/CAM systems use partially sintered Y-TZP ceramics, where the milling procedure is performed with the use of carbide burs in a dry environment. ${ }^{4}$

The most common failure in two-layer all-ceramic systems is the layered separation from the core. Delamination may occur due to patient-dependent factors, dynamic loads induced by premature contact, occlusal instability, inadequate bond strength, restoration geometry, material properties, material fatigue, inadequate core support, and incompatibility of heat expansion coefficients of the core and veneer. ${ }^{5}$

Although $\mathrm{ZrO}_{2}$ cores are highly resistant to fracture, veneer fracture poses a problem. ${ }^{6}$ Long-term clinical studies have demonstrated that $\mathrm{ZrO}_{2}$ core-veneer ceramic interface is the
License terms

ISSN 2321-1482. Pradesh University 
weakest structural component and that this bond is affected by the sensitivity of core surface finishing treatments such as veneer ceramic application method. ${ }^{7}$

Many variables may affect core-veneer bond strength, such as surface finish of the core that can affect mechanical retention, residual stresses generated by a mismatch in coefficient of thermal expansion (CTE), restoration geometry such as lack of proper veneering, ceramic support, inadequate framework design, and thickness of ceramic layers. The individual and combined effects of such variables can influence the core-veneer bond strength and therefore the clinical success rates of such restorations. ${ }^{8}$

The purpose of surface treatment was to clean the $\mathrm{ZrO}_{2}$ surface, increase surface roughness, and promote high surface energy and better wettability, thereby improving interfacial adhesion. ${ }^{6}$ Manufacturers recommend airborne-particle abrasion and liner application as routine pretreatment methods. These procedures significantly affect interfacial adhesion and failure mode. Reviewing the literature on the failure rates of core-veneered all-ceramic restorations revealed that delamination of the veneering porcelain from the core structure is a common failure mode.

There are different test methods for testing the core-veneer bond strength, such as shear bond strength (SBS) test, three- and -our point loading test, biaxial flexure strength, and direct compression.

The purpose of this study was to test the SBS of veneering ceramic to presintered zirconia cores after various surface treatments using SBS test and analyzing fracture pattern using scanning electron microscope (SEM).

\section{Materials and Methods}

Materials used in this study are as follows:

- Two stainless steel dies:

- Master die with disc-shaped mold space of 5-mm diameter and 2-mm height.

- Second die with disc-shaped mold space of 5-mm diameter and 4-mm height to accommodate presintered zirconia disc of $2 \mathrm{~mm}$ at the base.

- Commercially available presintered zirconia block (3M ESPE, Neuss, Germany).

- Prepared 40 zirconia core samples (-Fig. 1).

- Veneering porcelain (IPS e.max, Glidewell Laboratories).

- Silica-modified alumina particles $\left(110-\mu \mathrm{m} \mathrm{Al}_{2} \mathrm{O}_{3}\right)$.

- Ceramic Liner (ZirLiner, IPS e.max).

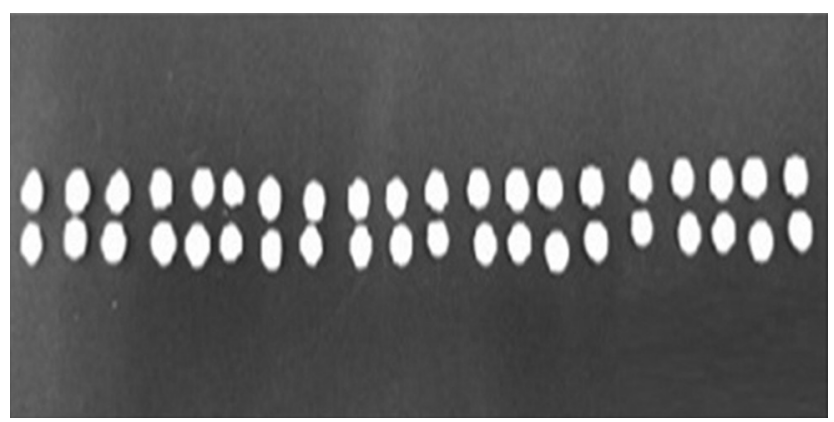

Fig. 1 Zirconia core samples.
- Hydrofluoric acid (10\%)

- Self-cure acrylic resin (DPI, Mumbai, India).

- Separating media.

Equipment used in the study are as follows:

- CAD/CAM System (3M ESPE).

- CNC Milling Machine.

- Universal Testing Machine (Tinius Olsen) (-Fig. 2).

- Scanning Electron Microscope (JSM-6100, Jeol Ltd., Tokyo, Japan) (-Fig. 3).

- Ceramic furnace (Ivoclar Vivadent P300, Ellwangen, Germany).

- Sandblasting unit (DENTSPLY, Konstanz, Germany).

- Ultrasonic cleaner.

\section{Methodology}

In total, 40 samples were prepared from presintered zirconia block and further divided into four groups of 10 each samples. Each sample was milled into disc-shaped measuring $5 \times$ $2 \mathrm{~mm}$ in dimension.

- Group 1: zirconia disc samples in this group were kept without any surface treatment (control group).

- Group II: zirconia disc samples in this group were abraded with silica-modified alumina particles of $110 \mu \mathrm{m}$ in size at an air pressure of $0.3 \mathrm{Mpa}$ from a fixed distance of $10 \mathrm{~mm}$ with the help of a sandblasting machine.

- Group III: samples in this group were coated with ceramic liner (IPS e.max ZirLiner). Ceramic liner powder was mixed with an appropriate amount of liquid as per manufacturer instructions. Surface on which the liner has to be

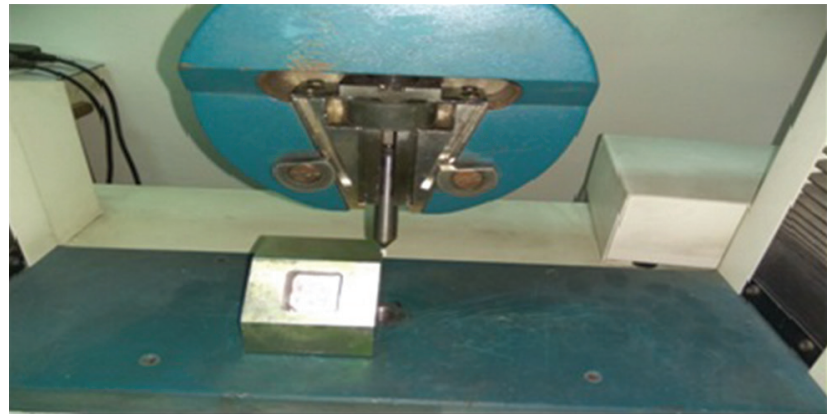

Fig. 2 Universal testing machine.

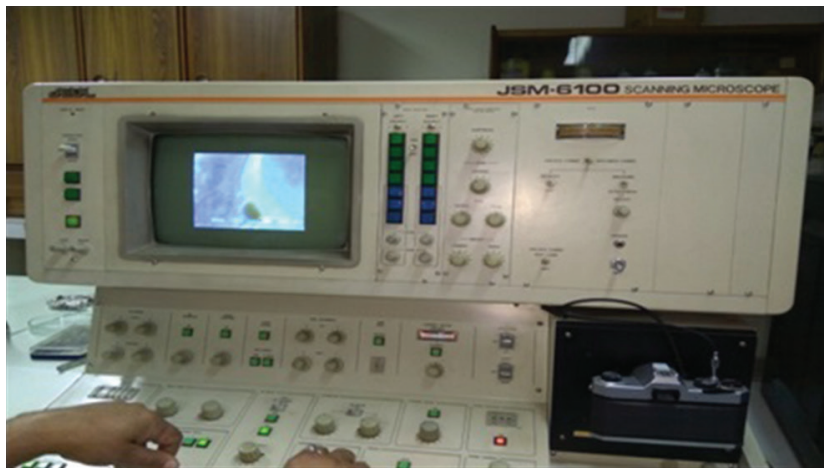

Fig. 3 Scanning electron microscope. 
applied was marked with a marker. After the liner coating, all the samples were fired for 15 minutes at $85^{\circ} \mathrm{C}$ in ceramic furnace.

\section{Veneering of Core Samples}

Second die was fabricated for accuracy of veneering layer of 2 -mm porcelain on zirconia samples. The internal measurement of mold prepared in the die was as follows: $5 \mathrm{~mm}$ in diameter and $4 \mathrm{~mm}$ in height. Zirconia core samples were then seated at the base of second die, which was carefully filled with porcelain mixed with the recommended liquid and then condensed on the disc inside the mold space. Excessive liquid was removed with the vibrate-and-wipe technique using absorbent paper.

All the zirconia core samples were then veneered with IPS e.max porcelain. The samples were removed carefully from the die with the help of a tweezer and placed on the furnace table for firing in Ivoclar Vivadent P300 ceramic furnace for 15 minutes at $750^{\circ} \mathrm{C}$. Then, a glaze firing of all the samples from each group in the Ivoclar Vivadent furnace was performed. Veneered disc samples were then arranged in their respective marked containers.

\section{Shear Bond Strength Test}

Veneered zirconia disc samples of each group were tested under a universal testing machine (Tinius Olsen) by placing them in a custom-made specimen holder. Load was applied along the long axis of samples close to the interface with a piston at a cross-head speed of $1 \mathrm{~mm}$ per minute. Maximum force was recorded at the time when delamination of veneer occurred, and SBS was calculated by dividing the load by bonded area (-Table $\mathbf{1}$ ).

\section{Scanning Electron Microscope Examination}

Samples of each group were then placed in a desiccator machine for 20 minutes to make them moisture-free. After the treatment in the desiccator machine, all the samples were coated with gold in a machine before SEM examination. After gold coating, samples of each group were examined under SEM to evaluate the fracture pattern, that is, adhesive fracture, cohesive fracture, or mixed fracture pattern. All the samples were seen under 200,500, and 1,000 magnification (-Figs. 4-6).

\section{Statistical Analysis}

The shear strength value of all the four groups was recorded. A master chart was prepared for all the data collected, entered in the computer in Microsoft Excel format, and analyzed using SPSS version. Analysis of variance and posthoc test were used for analysis ( - Tables $\mathbf{2}$ and $\mathbf{3}$ ).

\section{Results}

The samples in this in vitro study were divided into the following four groups:

- Group I: control group.

- Group II: sandblasted group.

- Group III: ZirLiner-coated group.

- Group IV: hydrofluoric acid treated group.

Table 1 Upper and lower mean values and standard deviation of the shear bond strength

\begin{tabular}{|c|c|c|c|c|c|c|c|c|}
\hline & \multirow[t]{2}{*}{$N$} & \multirow[t]{2}{*}{ Mean } & \multirow[t]{2}{*}{$\begin{array}{l}\text { Standard } \\
\text { deviation }\end{array}$} & \multirow[t]{2}{*}{$\begin{array}{l}\text { Standard } \\
\text { error }\end{array}$} & \multicolumn{2}{|c|}{$\begin{array}{l}\text { 95\% confidence interval } \\
\text { for mean }\end{array}$} & \multirow[t]{2}{*}{ Minimum } & \multirow[t]{2}{*}{ Maximum } \\
\hline & & & & & $\begin{array}{l}\text { Lower } \\
\text { bound }\end{array}$ & $\begin{array}{l}\text { Upper } \\
\text { bound }\end{array}$ & & \\
\hline 1 & 10 & 19.6440 & 1.97931 & 0.62591 & 18.2281 & 21.0599 & 16.04 & 22.03 \\
\hline II & 10 & 27.5180 & 1.58775 & 0.50209 & 26.3822 & 28.6538 & 25.14 & 30.03 \\
\hline III & 10 & 25.3130 & 1.17297 & 0.37093 & 24.4739 & 26.1521 & 23.26 & 27.13 \\
\hline IV & 10 & 22.9360 & 1.29351 & 0.40904 & 22.0107 & 23.8613 & 20.65 & 24.74 \\
\hline Total & 40 & 23.8528 & 3.30731 & 0.52293 & 22.7950 & 24.9105 & 16.04 & 30.03 \\
\hline
\end{tabular}

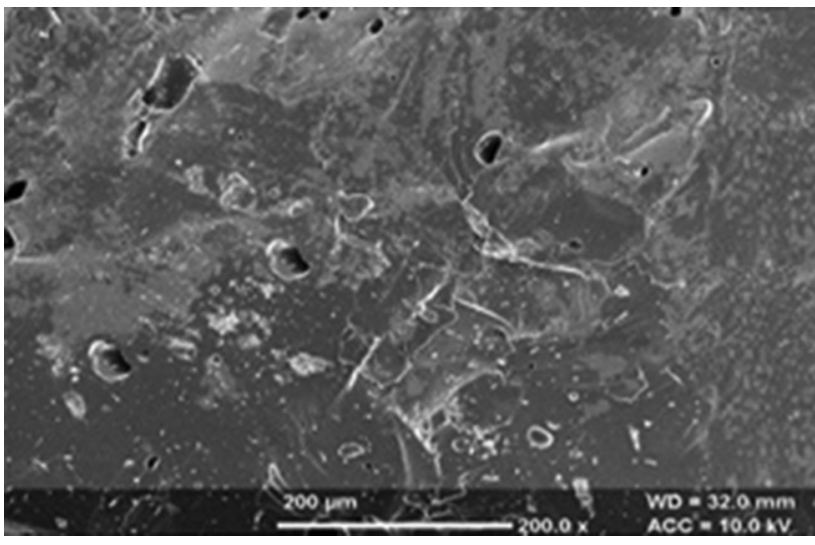

Fig. 4 Scanning electron microscope image at $\times 200$. WD, working distance.

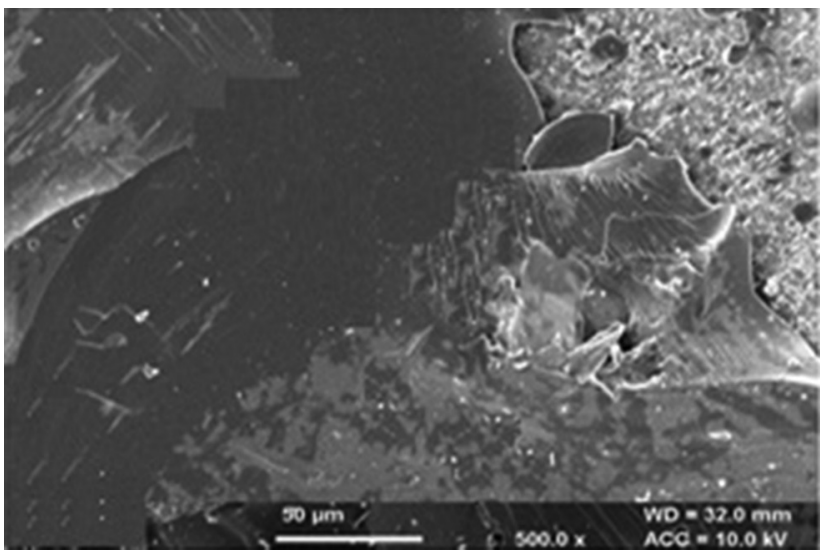

Fig. 5 Scanning electron microscope image at $\times 500$. WD, working distance. 
Group I had least value of shear bond strength (19.6440) and group II had the maximum (27.5180). Group II had higher value than groups III (25.3130), IV (22.9360), and I. Group III had higher value than groups IV and I (-Figs. 7-9).

SBS values are in following order:

Group II > Group III > Group IV > Group I.

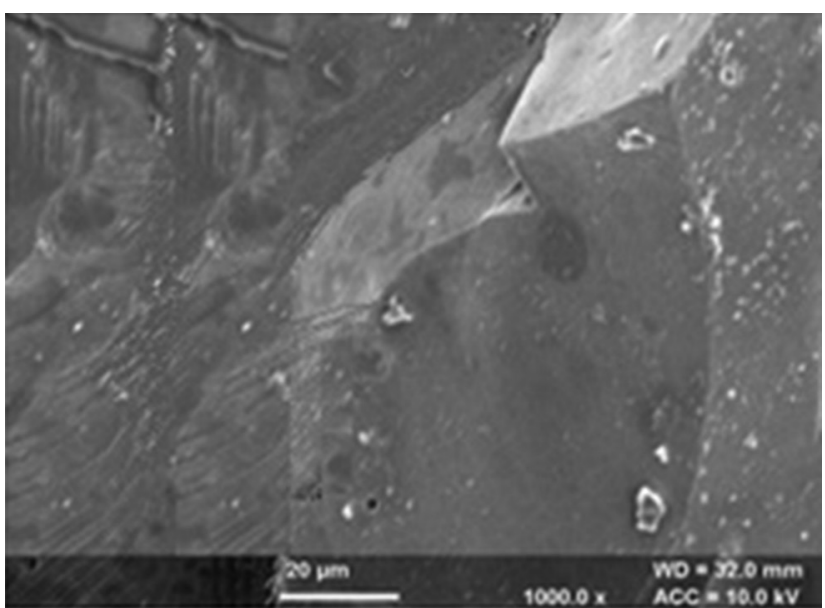

Fig. 6 Scanning electron microscope image at $\times 1000$. WD, working distance.

\section{Discussion}

The need for increased biocompatibility and better dental aesthetics led to the development of all-ceramic prosthodontic systems, which are increasingly applied, although their clinical performances and success have not been yet proven. All-ceramic dental restorations have a ceramic core instead of metal alloy and veneering ceramic porcelain in their composition.

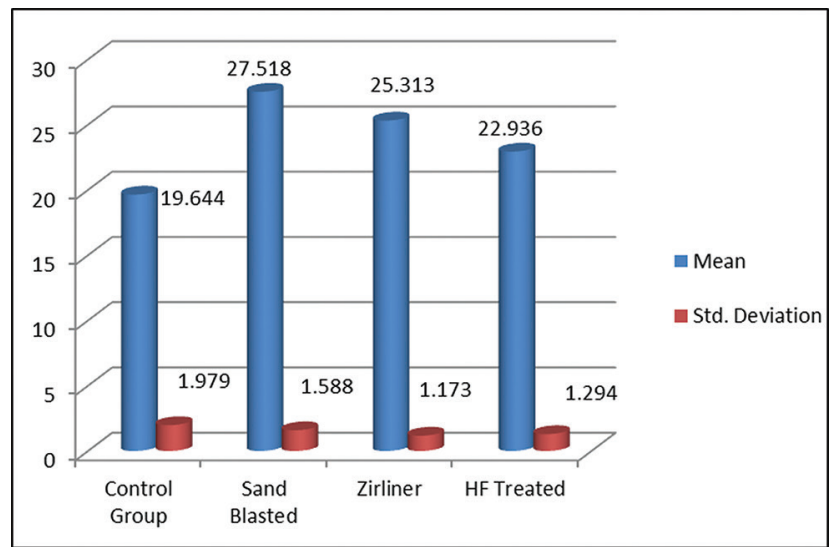

Fig. 7 Bar graph showing the upper and lower mean values and standard deviation of the shear bond strength. HF, hydrofluoric acid.

Table 2 Comparative shear bond strength values between the groups using analysis of variance

\begin{tabular}{|l|l|l|l|l|l|}
\hline & Sum of squares & $\begin{array}{l}\text { Degree of } \\
\text { freedom }\end{array}$ & Mean square & $\boldsymbol{F}$ & Significance \\
\hline Between groups & 341.204 & 3 & 113.735 & 47.951 & $<0.001^{\text {a }}$ \\
\hline Within groups & 85.389 & 36 & 2.372 & & \\
\hline Total & 426.593 & 39 & & & \\
\hline
\end{tabular}

aSignificant.

Table 3 Posthoc test used for multiple comparisons

\begin{tabular}{|c|c|c|c|c|c|c|}
\hline \multirow[t]{2}{*}{ I group } & \multirow[t]{2}{*}{ J group } & \multirow[t]{2}{*}{ Mean difference (I-J) } & \multirow[t]{2}{*}{ Standard error } & \multirow[t]{2}{*}{ Significance } & \multicolumn{2}{|c|}{$95 \%$ confidence interval } \\
\hline & & & & & Lower bound & Upper bound \\
\hline \multirow[t]{3}{*}{1} & 2 & $-7.87400^{\mathrm{a}}$ & 0.68875 & $<0.001^{b}$ & -9.7970 & -5.9510 \\
\hline & 3 & $-5.66900^{\mathrm{a}}$ & 0.68875 & $<0.001^{b}$ & -7.5920 & -3.7460 \\
\hline & 4 & $-3.29200^{\mathrm{a}}$ & 0.68875 & $<0.001^{\mathrm{b}}$ & -5.2150 & -1.3690 \\
\hline \multirow[t]{3}{*}{2} & 1 & $2.20500^{\mathrm{a}}$ & 0.68875 & $0.017^{\mathrm{a}}$ & 0.2820 & 4.1280 \\
\hline & 3 & $4.58200^{\mathrm{a}}$ & 0.68875 & $<0.001^{b}$ & 2.6590 & 6.5050 \\
\hline & 4 & $7.87400^{\mathrm{a}}$ & 0.68875 & $<0.001^{\mathrm{b}}$ & 5.9510 & 9.7970 \\
\hline \multirow[t]{3}{*}{3} & 1 & $-2.20500^{\mathrm{a}}$ & 0.68875 & $0.017^{\mathrm{a}}$ & -4.1280 & -0.2820 \\
\hline & 2 & $2.37700^{\mathrm{a}}$ & 0.68875 & $0.009^{b}$ & 0.4540 & 4.3000 \\
\hline & 4 & $5.66900^{\mathrm{a}}$ & 0.68875 & $<0.001^{\mathrm{b}}$ & 3.7460 & 7.5920 \\
\hline \multirow[t]{3}{*}{4} & 1 & $-4.58200^{\mathrm{a}}$ & 0.68875 & $<0.001^{b}$ & -6.5050 & -2.6590 \\
\hline & 2 & $-2.37700^{\mathrm{a}}$ & 0.68875 & $0.009^{b}$ & -4.3000 & -0.4540 \\
\hline & 3 & $3.29200^{\mathrm{a}}$ & 0.68875 & $<0.001^{b}$ & 1.3690 & 5.2150 \\
\hline
\end{tabular}

Note: I, main group; J, remaining groups.

aSignificant.

bHighly significant. 


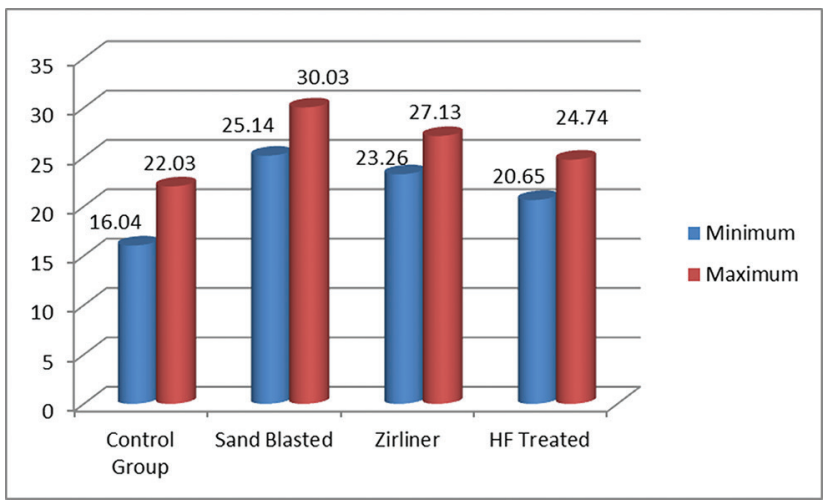

Fig. 8 Bar graph showing comparative shear bond strength values between the groups. HF, hydrofluoric acid.

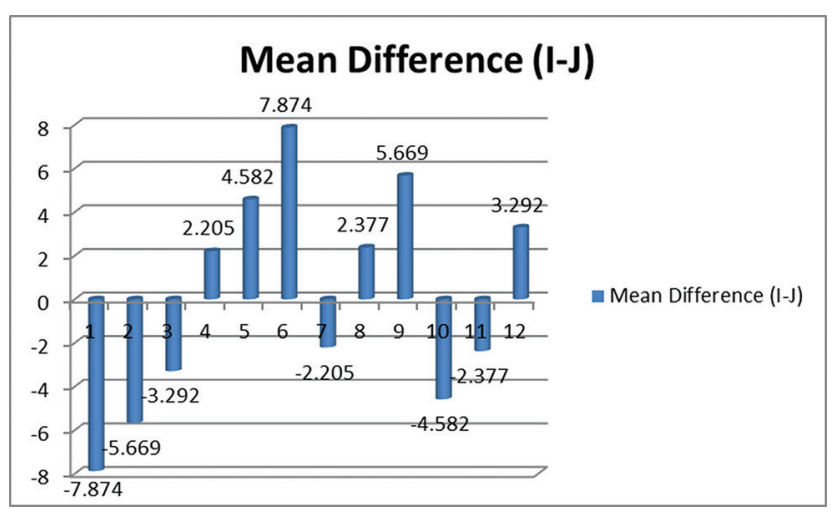

Fig. 9 Bar graph showing the mean difference (in Mpa). I, main group; J, remaining groups.

Zirconium dioxide as a core ceramic material for dental crowns and bridges possesses high strength, chemical stability, and availability in different hues of white color, with opportunity for superior aesthetics after veneering. ${ }^{9}$ Veneering porcelain for zirconia dioxide ceramics possesses the same strength as the materials for veneering of the metal core, but clinical practice showed that the prosthetic structures made of veneered zirconia often resulted in damage and fractured in the mouth. ${ }^{10}$ Damage occurs during the masticatory processes due to shearing of the fragments of porcelain mass and serious fractures of the zirconium base. ${ }^{11}$ Veneering ceramic is considered to be the weakest part of all-ceramic restorations and influenced by several factors such as thermal expansion mismatch, overload at the premature contacts, ceramic strength, and its adhesive bonding abilities. ${ }^{12}$

The strength of the zirconia-porcelain bonding depends on several factors such as zirconia surface, residual thermal stress, CTE, defects in materials, defects at the bonding interface, "wetting," and ceramic strength. Several different surface treatments are suggested for the improvement of the bonding procedures, such as mechanical surface roughening, tribochemistry and silanization, application of the liners, thermal spray, fusion with glassy balls, chlorosilane treatment with steam, selective infiltration etching that creates intergranular porosity, complex phosphate primer that react with hydroxyl groups, corrosion with hot solutions, and laser treatments (Nd:YAG [neodymium:yttrium aluminum garnet], $\mathrm{CO}_{2}$ ), among others. ${ }^{13}$

There are no standardized tests for measuring the bond strength of brittle all-ceramic restorations as for metal ceramics. Different testing methods have been used, such as macro and micro SBS test, three- and four-point bending tests, and microtensile test. They all have certain disadvantages, but SBS test is used in this study because of easy preparation of the samples and simple test protocol. There is a general consensus that airborne particle abrasion with 50 - to $110-\mu \mathrm{m}$ alumina particles at $0.25 \mathrm{MPa}$ is effective in roughening and cleaning the bonding surface of zirconia. However, the effect of those treatments on the mechanical properties of Y-TZP materials is controversial, and both positive and negative results have been described in the literature. Van et al conducted a study to evaluate the effect of hydrofluoric acid treatment on the surface microstructure of dental zirconia ceramics. Results of the study showed that hydrofluoric acid treatment was able to etch the zirconia ceramic, causing a variation in surface topography. ${ }^{14}$

Hydrofluoric acid is an inorganic acid of hydrogen fluoride. Industrially, hydrofluoric acid is used to etch silica-based materials, clean metal surfaces before electroplating, and etch silicon wafers in electronic semiconductor materials. Concentrations of 4 to $10 \%$ hydrofluoric acid are typically used in the dental clinic and dental laboratory. These concentration ranges are considered safe for dental applications. Chemically, hydrofluoric acid dissolves glass by reacting with silicon oxide, which is the main ingredient in glass. Dental porcelain consists of glassy and crystal phases; thus, hydrofluoric acid can dissolve the glassy phase, leaving the crystalline phase, creating surface roughness. ${ }^{14}$

Similar to the results in this study, Betamar et a ${ }^{15}$ obtained the highest bond strength by sandblasting $\left(110-\mu \mathrm{m} \mathrm{Al}_{2} \mathrm{O}_{3}\right)$ presintered zirconia. It was claimed that the difference from the control group was significant, and they found that the sandblasted group compared with the control group showed higher bond values on average.

In contrast to our findings, Kim et $\mathrm{al}^{16}$ performed sandblasting and sandblasting + liner treatments on KaVo Everest presintered $\mathrm{ZrO}_{2}$ cores and abraded control group surfaces with diamond discs alone. Cerabien ZR (Kuraray Noritake Dental Inc.) veneer ceramic was applied using the layering technique, and it was found that liner application markedly increased the failure rate of core-veneer bonds and reduced bond strength compared with sandblasting alone, which was in contrast to the finding in this study. Similar to the results in this study, Aboushelib et al achieved the highest bond strength with sandblasting in specimens to which NobelRondo veneer ceramic (Nobel Biocare) was applied. Significant differences were found to exist between sandblasting and control subgroups only in the Cercon and Procera groups. Harding et $\mathrm{al}^{17}$ in 2012 found that sandblasting increased $\mathrm{ZrO}_{2}$-veneering porcelain bond strength, with no difference between the control and sandblasting + liner groups.

SEM examination shows three types of fractures: adhesive fracture, cohesive fracture, and mixed type of fractures. 
In this study, it was found that predominantly occurring fractures are the mixed type of fractures, followed by adhesive and cohesive types of fractures. In the sandblasted group, there was cohesive fracture in the veneering porcelain, followed by adhesive fracture in the ZirLiner-coated group and mixed type of fractures seen in the hydrofluoric acid treated group and control group.

Teng J et $\mathrm{al}^{18}$ in 2012 found that liner coating significantly improved the zirconia-ceramic bonding, and these results were in contrast to those in this study.

The investigations in this study showed that various surface treatments improve the bonding between the zirconia core and veneering ceramic. Sandblasting treatment is more efficient in increasing the SBS as compared with ZirLiner-coated group and hydrofluoric acid treated group. Bond strength between the core and veneering ceramic plays an important role in the success of an all-ceramic restoration.

Therefore, these surface treatments must be used to improve the bond strength and achieve greater adhesive bonding values.

\section{Conclusion}

This in vitro study aimed to evaluate and compare the SBS of core-veneered zirconia restorations after various surface treatments of zirconia cores. A total of 40 disc-shaped zirconia samples were made. Surface treatment of these zirconia samples was performed with silica-coated alumina particles $(110 \mu \mathrm{m})$, ceramic liner (ZirLiner), and 10\% hydrofluoric acid. Samples in group I were kept without surface treatment as the control group. They were divided into groups of 10 each. SBS of all the core-veneered samples were tested under a universal testing machine. After the SBS test, all the fractured samples were analyzed under SEM to evaluate the fracture pattern (adhesive, cohesive, or mixed fracture). The overall mean SBS was 19.64 in group I, 27.51 in group II, 25.31 in group III, and 22.93 in group IV.

Therefore, within the limitations of this study, the following conclusions were drawn:

- Sandblasting of zirconia core with silica-coated alumina particles enhanced SBS significantly.

- Application of liner enhanced SBS significantly in comparison to the hydrofluoric acid treated group and control group.

- Treatment with hydrofluoric acid enhanced the SBS in comparison to the control group.

- To realize the benefit of the high strength of zirconia framework, the strength of veneering ceramics has to be improved.

As several parameters in the oral environment cannot be reflected in experimental studies, additional clinical studies with the aims of improving $\mathrm{ZrO}_{2}$ Core-Veneer bond strength and reducing complications are needed.

\section{Funding}

None.

\section{Conflict of Interest}

None.

\section{References}

1 Drummond JL, King TJ, Bapna MS, Koperski RD. Mechanical property evaluation of pressable restorative ceramics. Dent Mater 2000;16(3):226-233

2 Guazzato M, Albakry M, Ringer SP, Swain MV. Strength, fracture toughness and microstructure of a selection of all-ceramic materials. Part II. Zirconia-based dental ceramics. Dent Mater 2004;20(5):449-456

3 Denry I, Kelly JR. State of the art of zirconia for dental applications. Dent Mater 2008;24(3):299-307

4 Koutayas SO, Vagkopoulou T, Pelekanos S, Koidis P, Strub JR; Zirconia in Dentistry. Zirconia in dentistry: part 2. Evidence-based clinical breakthrough. Eur J Esthet Dent 2009;4(4):348-380

5 White SN, Miklus VG, McLaren EA, Lang LA, Caputo AA. Flexural strength of a layered zirconia and porcelain dental all-ceramic system. J Prosthet Dent 2005;94(2):125-131

6 Donovan TE. Metal-free dentistry. J Esthet Restor Dent 2005;17(3):141-143

7 Aboushelib MN, de Jager N, Kleverlaan CJ, Feilzer AJ. Microtensile bond strength of different components of core veneered all-ceramic restorations. Dent Mater 2005;21(10):984-991

8 Aboushelib MN, de Jager N, Kleverlaan CJ, Feilzer AJ. Microtensile bond strength of different components of core veneered all-ceramic restorations. Dent Mater 2005;21(10):984-991

9 Anusavice KJ. Mechanical properties of dental materials. In: Anusavice K, Shen C, Rawls HR, eds. Phillips' Science of Dental Materials. St. Louis, MO: Elsevier; 2003:521-530

10 Fischer J, Stawarczyk B, Hämmerle $\mathrm{CH}$. Flexural strength of veneering ceramics for zirconia. J Dent 2008;36(5):316-321

11 Stawarczyk B, Özcan M, Roos M, Trottmann A, Hämmerle CH. Fracture load and failure analysis of zirconia single crowns veneered with pressed and layered ceramics after chewing simulation. Dent Mater J 2011;30(4):554-562

12 Bonfante EA, Coelho PG, Guess PC, Thompson VP, Silva NR. Fatigue and damage accumulation of veneer porcelain pressed on Y-TZP. J Dent 2010;38(4):318-324

13 Kosmač T, Oblak Č, Marion L. The effects of dental grinding and sandblasting on ageing and fatigue behavior of dental zirconia (Y-TZP) ceramics. J Eur Ceram Soc 2008;28(5):1085-1090

14 Van Meerbeek B, Peumans V, Poitevin A, et al. Relationship between bond-strength tests and clinical outcomes. Dent Mater J 2010;26:100-121

15 Betamar N, Cardew G, Van Noort R. Influence of specimen designs on the microtensile bond strength to dentin. J Adhes Dent 2007;9(2):159-168

16 Kim HJ, Lim HP, Park YJ, Vang MS. Effect of zirconia surface treatments on the shear bond strength of veneering ceramic. J Prosthet Dent 2011;105(5):315-322

17 Harding AB, Norling BK, Teixeira EC. The effect of surface treatment of the interfacial surface on fatigue-related microtensile bond strength of milled zirconia to veneering porcelain. J Prosthodont 2012;21(5):346-352

18 Teng J, Wang H, Liao Y, Liang X. Evaluation of a conditioning method to improve core-veneer bond strength of zirconia restorations. J Prosthet Dent 2012;107(6):380-387 